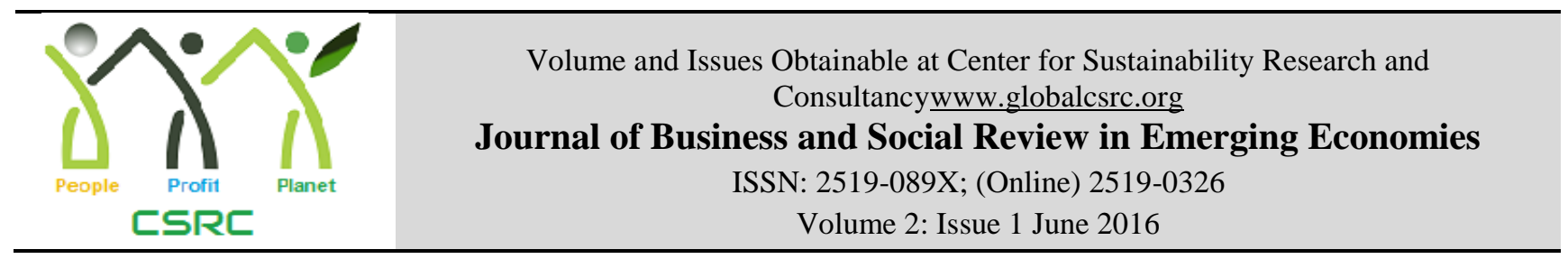

\title{
Influence of Strategic Planning on Crisis Management in the Service Sector Firms in Palestine
}

\author{
${ }^{1 *}$ Mohammed W. Almudallal, ${ }^{2}$ Hapriza Ashary, ${ }^{3}$ Syaharizatul Noorizwan Muktar \\ ${ }^{1} \mathrm{PhD}$ Scholar, Faculty of Management, UniversitiTeknologi Malaysia \\ mohwaleed1984@gmail.com \\ ${ }^{2}$ Senior Lecturer, Faculty of Management, UniversitiTeknologi Malaysia \\ hapriza@hotmail.com \\ ${ }^{3}$ Senior Lecturer, Faculty of Management, UniversitiTeknologi Malaysia \\ izatul@utm.my
}

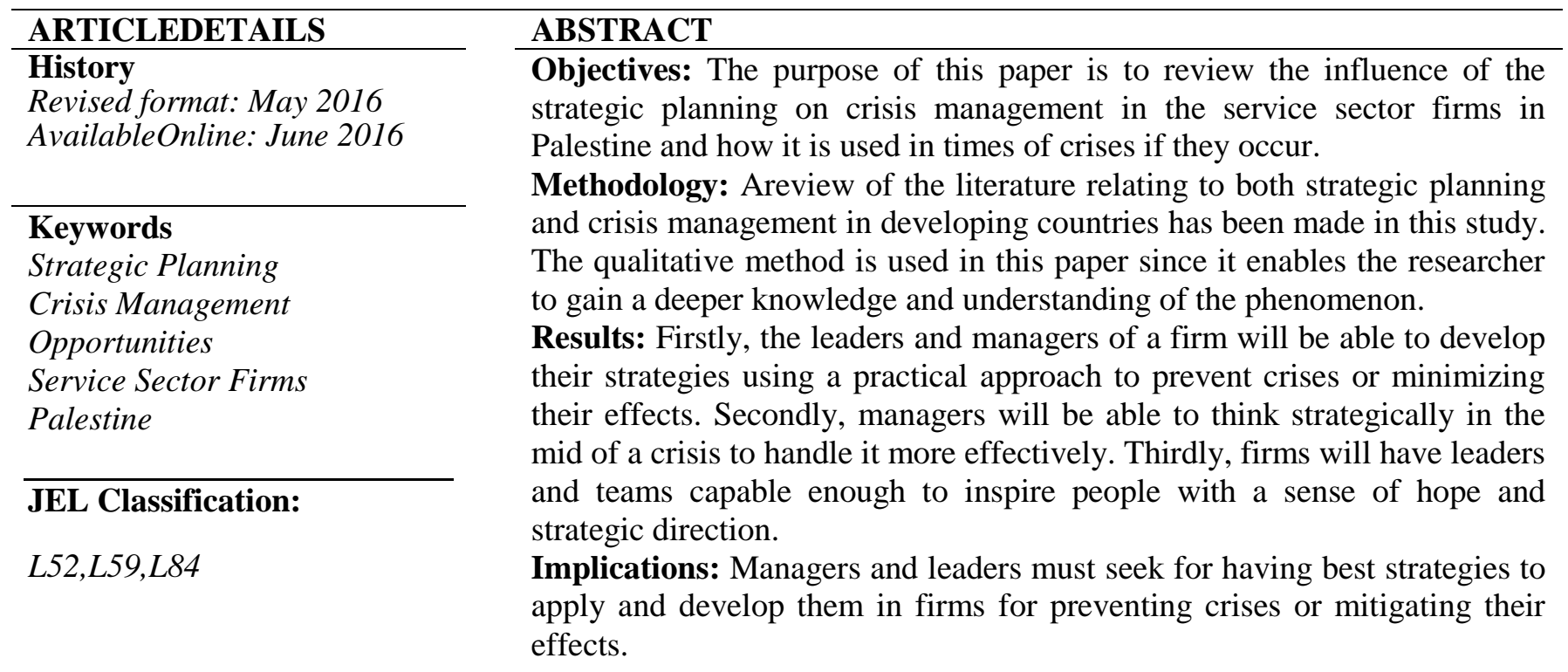

(C) 2016 The authors, under a Creative Commons AttributionNonCommercial 4.0

\section{Introduction}

In today's global competitive environment, the business has become more complicated and challenging, so any business large or small that is not managed strategically is very weak (Ocloo, et al., 2014; Nickols, 2016). Therefore, firms have to put in place the right strategies in order to embrace the changing situations (Oclooet al., 2014). Furthermore, the purpose of developing strategy is to outperform competition and to make difference in the market (Papulova and Papulova, 2006; Madu, 2013). Accordingly, strategy is to give a plan to achieve a firm's goals and objectives as well it is about

*Corresponding author's email address:mohwaleed1984@gmail.com

Recommended citation: Almudallal, M. W. Ashary, H. and Muktar, N. S. (2016). Influence of Strategic Planning on Crisis Management in the Service Sector Firms in Palestine. Journal of Business and Social Review in Emerging Economies, 2 (I), 
growing the business through the firm's resources (Madu, 2013). Due to the importance of strategy within firms, several authors have pointed out that the business goals are in need to be managed strategically in order to bring their aims to fruition at the end (Nickols, 2016). As a result, the concept of strategic management was created as it relates more to the managerial aspect of strategy (Fitzroy et al., 2012). Strategic management (SM) as stated by different scholars and researchers (e.g. Johnson et al., 2013; Ridwan, 2015) comprises of three main elements: strategy formulation, strategy implementation and strategy evaluation. In addition to the most comprehensive component in SM process which is strategic planning (SP) as it sets the basis for the other phases such as: strategy formulation, strategy implementation, strategy evaluation and control (Julian, 2013). Consequently, SP is essential in firms as it can contribute to long-term success and influence the progress of SM (Elbanna, 2016). In particular, creating strategic plans will set new opportunities for the firm to prosper as it is considered as a shield for the firm against any crisis that could attack the firm internally or externally (Bryson, 2011). Therefore, such studies as (Vargo and Seville, 2011) focused on developing an understanding the significance of SP as a way to improve organizational resilience to deal with crises and uncertainties that could attack the firm and weaken its power.

In other words, managing crises are still in need to be planned well (Coombs, 2014). Planning for crises and responding appropriately to them, will make the firm improves its abilities to survive and thrive (Vargo and Seville, 2011; Pal et al., 2014). Hence, Vargo and Seville (2011) believe that crisis management $(\mathrm{CM})$ focuses on coping with threats, while SP focuses on revealing opportunities. The use of SP in the time of crisis will significantly benefit the firm by having advantages to operate and compete and also to have resilience in dealing with uncertainties (Pal et al., 2014). Therefore, to be resilient, firms will need to use intensively SP in turbulent and changing situations in order to survive and thrive (Vargo and Seville, 2011; Ismail et al., 2011). Accordingly, the service sector firms (SSFs) can be more flexible than other firms. Since they have the sense of resilience; they can deal successfully with crises anywhere and anytime (Ocloo, et al., 2014). Although many firms especially in the service sector, plan and manage poorly, however, some of these firms have the potential to grow and develop their strategies in a very professional way (Kraus et al., 2013). While the significance of the service sector in value creation and employment has been considered, the role of services as providers of main contributions to service production, are often forgotten and ignored (Damuri, 2015).

SSFs suffer the negative effects of several crises, being at the sudden change of market attitudes and consumer expectations (Vargo\& Seville, 2011). Thus, they are highly affected particularly in times of crisis, also due to the limited financial and human resources to respond (Bourletidis, 2013). In fact, SSFs have the readiness and preparedness to implement strategic planning activities to overcome uncertainties (Ismail, et al., 2011; Pal, et al., 2014). This paper could be a pioneering and important study in the business environment due to the limited number of studies of strategic planning particularly in Palestine. 


\section{Literature Review}

\subsection{The Concept of Strategy}

In the new global environment which is characterized by rapid change and increasing competition, firms face hard threats that could affect their business and prevent its progress (Bouhali, et al., 2015), therefore the business environment has become more complicated and challenging (Ocloo, et al., 2014). This competitiveness will let firms create their own strategies to outperform competition and to make difference in the market (Madu, 2013). As a result, a well-designed strategy can help a firm to gain a competitive advantage and cope properly with dilemmas that harm the firms in the long run (Bouhali, et al., 2015). Consequently, the firm in this context enables itself to be in the front and it can hardly be duplicated by competitors (Mnjala, 2014).

\subsection{Definition of Strategic Planning}

The concept of strategic planning (SP) which has evolved over several decades is a critical component in strategic management literature (Brews and Purohit, 2007). The field of strategic planning has attracted important attention by academics and practitioners alike, and the benefits of engaging in systematic strategic planning are well documented (Rudd, 2005; Brews and Purohit, 2007). Stonehouse and Pemberton (2002) claim that strategic planning is the developing and formulation of organisational level which sets general and flexible objectives, strategies and policies of a business, leading the firm towards its vision of the future (Aldehayyat and Anchor, 2010). Therefore, strategic planning is regarded as an essential tool of management in firms that aim to guide and ensure that the appropriate resources are available at a suitable place and time for achieving objectives.

\subsection{Strategic Planning Process}

The development applied to the strategic planning processes today is very essential in the strategic planning field (Frost, 2003). The strategic planning process is the most important step. As Bryson (1995) argues, the central goal is to get main organizational decision makers and agree that strategic planning is needed and desirable in firms. As well as, the importance of the strategic planning process has resulted in a number of tools being developed to evaluate the process and to identify organisational strengths, weaknesses, opportunities and threats (Murphy, 2011). Considerably, Gates (2010) states that, the typical strategic planning processes examine an organization's current environment (e.g. the present situation of the organization's mission, guiding principles), expectations about how it would like to grow or evolve (the desired future), its objectives as an organization (what it will strive to do), and its intentions for moving forward (how it will move forward to achieve its objectives). This clarification mostly leads to better understanding the process of strategic planning as a whole.

\subsection{The Concept of Crisis}

Understanding and dealing with crises is becoming today, a real challenge as it is not only to recognize crises, but also to realize them on time (Darling, et al., 2005). The term "crisis" will clearly vary from one firm to another, however, the label is not that important but What matters is the overall approach in which the firm carefully and continually re-examine operations in all fields and plans for how crises, can be suitably managed (Darling, et al., 2005). Millar (2004) viewed crisis as an event which suddenly occurs, demands a fast response, creates uncertainty and pressure, threatens the reputation and continuously changes the firm (Ulmer et al., 2014). The numerous classification models in the study explain that scholars categorize crises according to the source of crisis, scope of impact and character. These three dimensions are the key elements of the crisis-type triangle shown in the figure (Figure 2.1). 


\section{Figure 2.1 Types of crisis triangle}

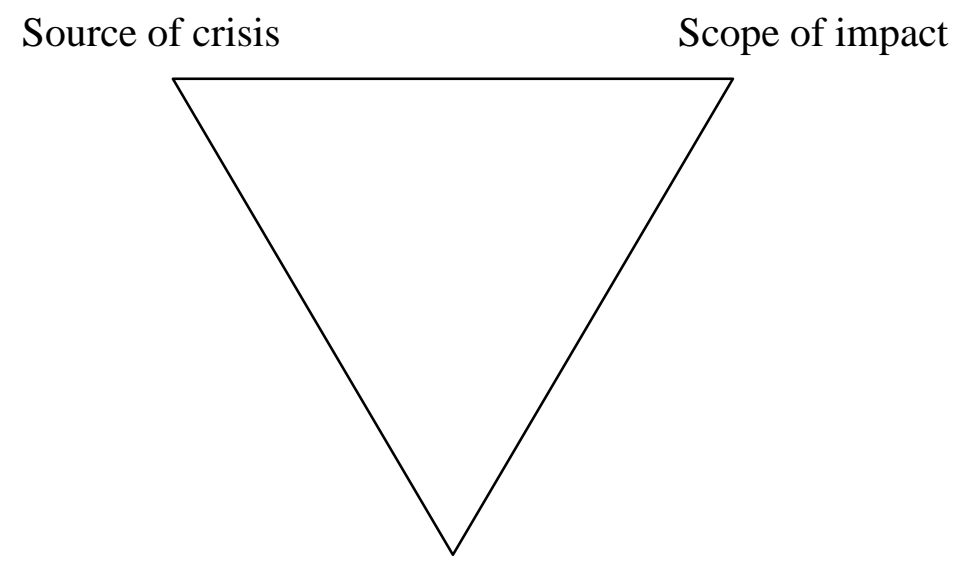

Figure 2.1

Character of crisis

To summarize, Mitroff (2005) typology, represents and covers other scholars' classifications as it is more obvious and suitable for this paper. It is the responsibility of managers and leaders in firms to consider all these types as possibilities for crises and have strategic and tactical plans, as a result crises could be rapidly resolved or prevented from happening. Therefore, Mitroff's classification of crisis types was selected, furthermore, it is supported by Sher (2006), and developed by Alas' (2009). Previous studies such as (Gao, 2010) has exposed that over half of all crises were economic/financial crisis and the second type was reputational crisis while the third was human resources crisis. Physical and informational crises, natural disasters and psychopathic acts happen after the top three main crisis types. Goa defined those three major types of crisis: economic, reputational and human resources and explained the interconnection between them by giving the instructions of how to make appropriate managerial plans to alleviate the negative crisis effects.

\section{Figure 2.2 The main types of crisis}

Reputational HR 


\section{Economic}

In addition to another type of crisis, added by the author, as it explains the current case study, which is called "geopolitical crisis". It is equally as important as the aforementioned main types of crisis in firms and organizational work. Importantly, the geopolitical issues of Palestine have been mostly ignored by politicians and decision makers. The geopolitical dimension should not be underestimated as it is considered as one of the most important crisis type in this regard. The Palestinians are trapped in regional geopolitics. As well as, their territories are divided into two widely separated areas: Gaza Strip and West Bank and both have an economic catastrophe and harsh restrictions in their daily life (Friedman, 2009). Considerably, Gaza is the case study to take into account and to show how the geopolitical aspect grows up and affects the daily life. Since the blockade on Gaza in 2007, the situation was getting worse and still impacts the all aspects of Gazans life. Gaza Strip is still suffering from the ongoing closure on the transport of goods and services from Gaza to its traditional markets in the West Bank and other parts of Palestine. Along with the severe restrictions on access to agricultural land, fishing and water which prevent supportable growth and keeps up the worst levels of unemployment, food scarcity, fuel and medication (Al-Modallal, 2015). In short, geopolitical environment is to be added to the previous types; however this addition will make the firm more distinguished and characterized with unique and effective strategies for coping with crises in the short and long terms.Confirming on that also for what was stated by Pollard and Hotho (2006) that the more a firm is prepared for crisis situations, the better it can be managed as well as in decision making to minimize the effects when the crisis occurs. The developed square figure is illustrated in figure 1.4. Gao and Alas (2010) asserted that the empirical studies in other countries could expand the range for what is suitable to the targeted issue to be studied in the future.

Figure 2.3 The developed figure of types of crisis

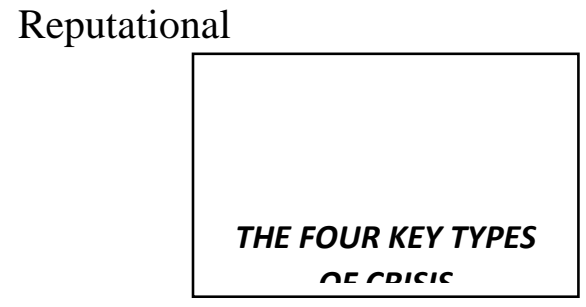

Economic
HR

\author{
Geopolitical
}

\subsection{Crisis Strategic Planning}

In today's business world, the most important issue especially in managing crises is that managers should be prepared very well for uncertainty (Vargo and Sevllie, 2011). Managers who fail to recognize the crisis and do not have a plan for it they will be suffered serious troubles. Otherwise, crises can lead to decline the firm any time if not handled immediately by managers and who are in charge. (Pollard and Hotho (2006) stated that the more a firm is prepared for crisis situations, the better it can be managed. Consequently they emphasize the significance of implementing strategic plans to get fully prepared for any crisis that occurs. As well (Reilly, 2008) has pointed out that actual internal and external strategic 
planning is needed during a crisis. As a result, effective crisis plan is able to prevent any potential problems and manage any crises that could harm the firm and it can bring the firm a more positive reputation than it had before the crisis (Ulmer et al., 2014). Crisis management will not succeed without planning. Consequently, crisis planning needs to be conducted appropriately during a crisis. In the same context strategic actions to manage the crises require a crisis management process and strategic planning in the firm. These actions which firms can do during crisis include realizing crises and prioritizing them based on the firm's needs and wants, identifying effective factors on the occurrence of crises and their importance, providing necessary facilities to control crises and reduce their negative effects. Thus crisis strategic planning (CSP) becomes essential in supporting resilience which is the ability to rapidly recover from difficulties and crises. Resilient firms show more preparedness and flexibility in dealing with crises while the less resilient firms lack of strategic readiness (Pal, et al., 2014). Resilience as well is the capability of the firm, not only to survive (crisis management) but also to thrive (strategic planning) in facing crises when they occur.

\section{Methodology}

The constructive methodological approach is chosen in this study, which has enabled to reveal the estimation of the crisis and to develop the researcher's attitude to the researched problems. Review of literature in this field has been helpful in developing the elements of strategic planning process to enhance the managerial capability for crisis management (Valackiene, 2015). A primary focus of this paper is to investigate the strategic planning process and looking into what strategic processes managers and leaders may use for preventing crises or mitigating their effects.

\section{Findings/Discussion}

Firstly, the managers and leaders of this firm will be able to develop their strategies using an influential practical strategic approach to prevent crises or minimizing their effects. Secondly, managers will be able to think strategically during a crisis, and to do this most effectively. Thirdly, the firms will have leaders capable to inspire people with a sense of hope and direction. Fourthly, firms will have better ability to plan and make decisions carefully and efficiently for more influential responses to crises. Finally, firms will have teams that can recognize methods and turn the chaotic situations into opportunities for their firms to operate and compete.

\section{Conclusion/Implications}

Today's business has become more challenging, and making strategy is very important to the firm, therefore, setting strategies can be used in the unstable environments whatever they are (Bouhali, et al., 2015). Considerably, SP is regarded along with CM as a backbone to the firm in confronting and controlling crises that occur. SP is highly recommended by some authors particularly in the service sector firms (SSFs). Effective crisis strategic planning is regarded as a process of not only surviving but also a process of thriving to operate and compete. The traditional approaches of service recovery have focused deeply on damage limitation and service continuity after damage and have neglected the more critical area of crisis strategic planning to not only to survive but also to thrive (Vargo\& Seville, 2011). 


\section{References}

Alas, R. (2009). The triangular model for dealing with crisis management. Managing in a Global Economy XIII, by JK Miller, Rio de Janeiro, Brazil, June, 21-25.

Aldehayyat, J. S., \& Anchor, J. R. (2010). Strategic planning implementation and creation of value in the firm. Strategic change, 19(3-4), 163-176.

Al-Modallal, W. (2015). The Impact of Egyptian Actions on the Future of the Relationship with the Resistance in the Gaza Strip (Strategic Assessment-38). Al Zaitouna Centre for Studies and Consultations. Gaza. Palestine.

Bouhali, R., Mekdad, Y., Lebsir, H., \&Ferkha, L. (2015). Leader Roles for Innovation: Strategic Thinking and Planning. Procedia-Social and Behavioral Sciences, 181, 72-78.

Bourletidis, K. (2013). The strategic management of market information to SMEs during economic crisis. Procedia-Social and Behavioral Sciences, 73, 598-606.

Brews, P. and Purohit, D. (2007), "Strategic planning in unstable environments", Long Range Planning, Vol. 40 No. 1, pp. 64-80.

Bryson, J. M. (1995). Strategic planning for public and nonprofit organizations: A guide to strengthening and sustaining organizational achievement (Rev. ed.). San Francisco, CA: JosseyBass Publishers.

Bryson, J. M. (2011). Strategic planning for public and nonprofit organizations: A guide to strengthening and sustaining organizational achievement (Vol. 1). John Wiley \& Sons.

Coombs, W. T. (2014). Ongoing Crisis Communication: Planning, Managing, and Responding: Planning, Managing, and Responding. Sage Publications.

Damuri, Y. R. (2015). Services Sector Development and Improving Production Network in ASEAN (No. 24821).

Darling, J., Seristo, H., \&Gabrielsson, M. (2005). Anatomy of crisis management: a case focusing on a major cross-cultural clash within DaimlerChrysler 3, $343-360$.

Elbanna, S. (2016). Managers' autonomy, strategic control, organizational politics and strategic planning effectiveness: An empirical investigation into missing links in the hotel sector. Tourism Management, 52, 210-220.

FitzRoy, P., Hulbert, J., Ghobadian, A., \&O'Shannassy, T. (2012). Strategic management: the challenge of creating value. Routledge.

Friedman, G. (2009). The Geopolitics of The Palestinians. The Officer: Reserve Officers Association National Security, Report, pp, 2-16. Stratfor. Texas.

Frost, F. A. (2003). The use of strategic tools by small and medium-sized enterprises: an Australasian study. Strategic change, 12(1), 49-62.

Gao, J. (2010). Human Resource and Reputational Crises in Chinese Organizations (Doctoral dissertation, Thesis of the degree of Doctor of Philosophy. Estonian Business School, 2010.-192 p).

Gates, L. P. (2010). Strategic planning with critical success factors and future scenarios: An integrated strategic planning framework (No.CMU/SEI-TR-037).

Ismail, H. S., Poolton, J., \&Sharifi, H. (2011). The role of agile strategic capabilities in achieving resilience in manufacturing-based small companies. International Journal of Production Research, 49(18), 5469-5487.

Johnson, G., Whittington, R., Scholes, K., Angwin, D., \&RegnŽr, P. (2013).Exploring strategy text \& cases. Pearson Higher Ed.

Jullian, O. (2013). Relationship between Strategic Planning and Orgnisation's performance in NGOs: A Case of Actionad, Kenya. (Doctoral dissertation, SCHOOL OF BUSINESS, UNIVERSITY OF NAIROBI).

Kraus, S., Moog, P., Schlepphorst, S., \&Raich, M. (2013). Crisis and turnaround management in SMEs: a qualitative-empirical investigation of 30 companies. International Journal of Entrepreneurial 
Venturing, 5(4), 406-430.

Madu, B. C. (2013). Vision: The relationship between a firm's strategy and business model. Journal of Behavioral Studies in Business, 6, 1.

Mitroff, I.I. (2005), Why Some Companies Emerge Stronger and Better from a Crisis, 7 Essential Lessons for Surviving Disaster, New York: Amacom.

Murphy, R. (2011). Strategic Planning in Irish Quantity Surveying Practices. Doctoral Dissertation. Heriot-Watt University. Edinburgh Business School. U.K

Nickols, F. (2016). Strategy, strategic management, strategic planning and strategic thinking. Distance Consulting LLC.

Ocloo, C. E., Akaba, S., \&Worwui-Brown, D. K. (2014). Globalization and Competitiveness: Challenges of Small and Medium Enterprises (SMEs) in Accra, Ghana. International Journal of Business and Social Science, 5(4).

Pal, R., Torstensson, H., \& Mattila, H. (2014). Antecedents of organizational resilience in economic crises-an empirical study of Swedish textile and clothing SMEs. International Journal of Production Economics, 147, 410-428.

Papulova, E., \&Papulova, Z. (2006). Competitive strategy and competitive advantages of small and midsized manufacturing enterprises in Slovakia. E-Leader, Slovakia.

Ridwan, M. (2015). Strategic planning practices. An empirical study in the Indonesian banking industry (Doctoral dissertation, University of Southampton).

Rudd, J. M. (2005), A multivariate examination of the relationship between strategic planning and organizational performance, Ph.D., Aston, 54-8175.

Sher, L. (2006), Enterprise crises types and exhibition, Chinese Information, October 11, pp. 6.

Stonehouse, G. \& Pemberton, J. (2002), "Strategic planning in SMEs-some empirical findings", Management Decision, Vol. 40 No. 9, pp. 853-61.

Ulmer, R.R., Sellnow, T.L., \& Seeger, M.W. (2014), Effective Crisis Communication: Moving from Crisis to Opportunity. Thousand Oaks: Sage Publications.

Valackiene, A. (2015). Theoretical substation of the model for crisis management in organization. Engineering Economics, 22(1), 78-90.

Vargo, J. \& Seville, E. (2011). 'Crisis strategic planning for SMEs: finding the silver lining',

International Journal of Production Research, Vol. 49, No. 18, pp.5619-5635. 